\title{
Finding Teens in TheirSpace: Using Social Networking Sites to Connect Youth to Sexual Health Services
}

\author{
Lauren J. Ralph • Nancy F. Berglas • \\ Sarah L. Schwartz • Claire D. Brindis
}

Published online: 22 February 2011

(C) The Author(s) 2011. This article is published with open access at Springerlink.com

\begin{abstract}
The increasing popularity and widespread use of the Internet has made it an emerging venue for delivering health-related messages and interventions. The current study explored the potential for using social networking sites (SNS), specifically MySpace, to connect youth to sexual health services. Surveys and focus groups with youth aged 14-19 living in low-income communities in California revealed high levels of overall Internet access, frequent use of SNS, and experience in searching for health information online. However, disparities in frequency and location of Internet access by race/ethnicity, and hesitancy among some youth to join a clinic's online social network, may affect the success of this new strategy in some populations. Interviews with clinic staff highlighted the successes and challenges of using MySpace as part of their outreach efforts. Staff described balancing the benefits of web-based outreach, including its low cost, wide reach, and teen friendliness, with its challenges, including overcoming technological barriers, ensuring teens' safety from inappropriate contact, and remaining timely and relevant given the dynamic nature of the Internet. This study indicates that SNS and other technologies have strong potential for
\end{abstract}

L. J. Ralph $(\varangle) \cdot$ N. F. Berglas · S. L. Schwartz $\cdot$ C. D. Brindis Philip R. Lee Institute for Health Policy Studies

Bixby Center for Global Reproductive Health,

University of California, San Francisco,

3333 California Street, Suite 265,

San Francisco, CA 94143-0936, USA

e-mail: Lauren.Ralph@ucsf.edu

C. D. Brindis

National Adolescent Health Information and Innovation Center, University of California, San Francisco,

3333 California Street, Suite 245,

San Francisco, CA 94143-0503, USA reaching diverse youth with critical health information when implemented as part of a comprehensive outreach strategy.

Keywords Teen pregnancy prevention - Adolescents · Reproductive health · Outreach · Internet · Evaluation

\section{Introduction}

Over the past decade, adolescents' use of the Internet and other technologies has increased dramatically. In 2009, the vast majority (93\%) of American youth aged 12-17 reported using the Internet, a significant increase from $74 \%$ in 2000 . Teens' frequency of Internet use and diversity of online activities has also increased, making them one of the most "wired" demographic groups today. Two thirds of teen Internet users in 2009 reported going online daily, and of those, $36 \%$ did so several times a day (Lenhart et al. 2010).

Adolescents use the Internet for many purposes; according to national survey data, their most frequent online activity is the use of social networking sites (SNS) such as MySpace or Facebook (Rideout et al. 2010). In 2009, nearly three-quarters $(73 \%)$ of online teens reported using these interactive sites, an increase from $55 \%$ in 2006 (Lenhart et al. 2010). In 2007, MySpace was the most popular SNS among teens; in that year, $85 \%$ of teen SNS users had a profile on MySpace, compared to $7 \%$ on the second most popular site, Facebook (Lenhart and Madden 2007).

Adolescents report using these networks primarily to extend and strengthen the friendships and relationships they have established in their non-virtual lives (Subrahmanyam and Greenfield 2008; Ito et al. 2008). Their SNS activities 
include sending group $(50 \%)$ or private $(66 \%)$ messages, posting comments to a friend's blog $(52 \%)$ or pictures $(83 \%)$, and commenting on a friend's page or wall post $(86 \%)$. In addition, over one-third $(37 \%)$ of teens report joining a group on a SNS (Lenhart et al. 2010), including health-related interest groups (Versteeg et al. 2009). Accordingly, online interaction via SNS may have many positive effects on a teen, offering a unique and dynamic venue for self-expression, communication, and identity formation (Berson et al. 2002; Ito et al. 2008; Boyd 2007).

\section{A Digital Divide?}

While among teens overall Internet use is high, there has been continued concern about the existence of a "digital divide," with teens from families with higher socioeconomic status (SES) having greater access to new technologies than those from lower SES families. The most recent data suggest that disparities in access may be finally shrinking. A 2009 Kaiser Family Foundation survey of 8 - to 18 -year-olds and their parents found that while $91 \%$ of homes where at least one parent had a college education had Internet access, this figure declined to $74 \%$ among households where the parent's education did not extend beyond high school. However, despite being less likely to have Internet access at home, Hispanic and African American teens reported spending more time daily online than their white peers, suggesting that teens have diverse points of access to the Internet, including school, friends' houses, and the library (Rideout et al. 2010). In addition, although the computer remains the most common source of Internet access for teens, a growing minority gain access through cell phones (27\%) and/or gaming devices $(19 \%$; Lenhart et al. 2010). Regarding use of SNS specifically, national survey data from the Pew Internet \& American Life Project found that teens from lower income families, defined as those earning $<\$ 30,000$ annually, were more likely to use SNS than their wealthier peers (Lenhart et al. 2010). Still, location may create a particular barrier for low SES teens as Internet access in public settings may be more limited due to time and resource constraints, filtering software, and potential loss of privacy.

\section{Using the Internet for Health Promotion}

Given its tremendous popularity and widespread availability, the Internet has emerged as a key venue for delivering health-related messages and interventions to adolescents (Stretcher 2007; Guan and Subrahmanyam 2009). Inherent advantages include its cost-effectiveness in reaching a large target audience, convenience and flexibility for potential users, capacity for personalization based on user characteristics or feedback, timeliness, and ability to overcome geographic- and time-based barriers (Griffiths et al. 2006; Roberto et al. 2007).

Moreover, surveys of teens demonstrate that they are interested in receiving health information and prevention messages online, in particular on sensitive topics such as sexual health, and have experience using the Internet to search for health-related content (Gray and Klein 2006; Ybarra and Suman 2008; Borzekowski and Rickert 2000, 2001). The relative anonymity and privacy offered by the Internet are considered as key determinants of its appeal to adolescents (Griffiths et al. 2006; Gustafson et al. 1999). Teens generally feel comfortable assessing the trustworthiness and saliency of health information found online, enabling them to avoid the time, possible costs, and concerns about confidentiality associated with visiting a health care provider (Gray and Klein 2006; Kanuga and Rosenfeld 2004).

Despite its clear advantages, using the Internet to reach teens and convey sensitive health information is associated with certain challenges. Internet-filtering software, low bandwidth Internet connections, and difficulty finding a private location from which to access the Internet can serve as barriers to accessing sensitive health information online (Skinner et al. 2003). The prevalence of online pornography provides an additional obstacle to finding accurate sexual health information online. In a 2000 study, when investigators searched keywords related to teen sexual health, $63 \%$ of the returned sites were found to be pornographic (Smith et al. 2006). A further challenge may be finding a site that is comprehensive in content, linguistically and culturally appropriate, and also teenfriendly. A content analysis of 36 educational sexually transmitted infection (STI)/HIV web sites in 2002 revealed not only difficulty locating specific types of information but also gaps in the information presented. Additionally, the average reading level of the sites was at ninth grade, which may be above that of many teens at risk for contracting an STI (Keller et al. 2002). A final challenge inherently associated with online information searching is "information overload," which can lead to difficulty finding accurate, trustworthy information (Kanuga and Rosenfeld 2004).

Social Networking Sites as a Venue for Health Outreach

Although a growing body of research has studied the successes and challenges of using the Internet to deliver health-related information and interventions, less is known about using SNS in particular. Given their increasing popularity and more recent emergence as a critical element among teens, SNS may have the potential to reach a large and diverse population with frequent, quick, and tailored messages. 
In recent years, teen-oriented, non-profit organizations have begun to use this tactic to spread their messages. Sex, Etc., a national magazine and web site on teen sexual health, has a MySpace profile where teens can learn about the organization, become "friends" with the organization, post comments, and exchange messages with Sex, Etc. staff. The public sector has also become involved in using SNS to promote public health messages. In 2008, the New York City Department of Health launched a MySpace page in response to increasing rates of teen depression and suicide. The page involves teen characters' video blogging about their health; it received over 11,000 hits within the first few days of its launch (NY1 2008).

Along with their tremendous popularity among youth, SNS have received negative attention because of the perceived risks associated with having a presence online, including exposure to sexually explicit material and online victimization in the forms of sexual solicitation and harassment (Guan and Subrahmanyam 2009). However, a minority of online teens report having been the victim of online harassment $(9 \%)$ or unwanted sexual solicitation (4\%; Mitchell et al. 2007; Ybarra et al. 2007). Perhaps not surprising is that the occurrence of this unwanted contact is higher among teens who display risk behavior information online as part of their social network profile (Ybarra and Mitchell 2007).

Thus, SNS may prove to be an important venue for reaching teens with brief health promotion messages and information about available services. Similar to existing forms of health outreach, it finds teens where they are most comfortable, in "TheirSpace." However, even though youth-serving organizations are spending time and resources to implement SNS outreach, little is known about the potential successes and challenges of this emerging strategy. The purpose of this study was to explore Internet and SNS use among a sample of low-income California youth and to describe efforts by California family planning clinics to conduct health outreach using SNS.

\section{Methods}

The current study was conducted as part of an ongoing evaluation of California's TeenSMART Outreach (TSO) Program, a state-funded teen pregnancy prevention effort to increase access to clinical family planning services for teens living in low-income communities with high teen birth rates. From 2004 to 2008, 21 non-profit and public sector clinics were funded to develop and implement varied outreach strategies to reach teens aged 14-19. All clinics also received funding through California's Family Planning, Access, Care and Treatment (PACT) Medicaid waiver program, which provides no-cost, confidential sexual health services to low-income uninsured residents, including teens. As of January 2008, when this study began, 7 of the 21 TSO clinics were using MySpace as a strategy for reaching teens with information about the sexual health services offered at their clinic sites. No clinics reported using other SNS (such as Facebook); therefore, this study focused on the use of MySpace.

This study was designed by researchers at the University of California, San Francisco (UCSF) to explore these emerging efforts and understand their potential as a model for other youth-serving programs in California. Specifically, the study aimed to answer the following research questions:

1. To what extent do teens in low-income California communities have access to the Internet and use SNS? Does this profile differ by age, gender, or racial/ethnic background?

2. To what extent do teens use the Internet to find information about sexual health and what are teens' perceptions of the information available online?

3. From the clinic perspective, what are the resource requirements, advantages, and challenges of implementing and maintaining web-based outreach using SNS?

To conduct this formative evaluation, the research questions were addressed using a mixed method approach. All data collection strategies were developed by the UCSF researchers specifically for this study. Wherever possible and to build upon previously used items, questions mirrored the Pew Internet \& American Life Project's survey instrument (Lenhart and Madden 2007). All research activities were approved by UCSF's Committee on Human Research and the State of California's Committee for the Protection of Human Subjects. Active verbal consent was obtained from all participants, following receipt of an information sheet detailing the risk and benefits of participation in the study. Parental consent was not required due to the content and setting of the study.

\section{Teen Internet Access and Use Survey}

Researchers developed a brief (two-page, 18-item) survey designed to assess teens' access to and use of the Internet and SNS, and interest in seeking sexual health information online. Program staff at all TSO clinics $(N=21)$ were asked to administer at least 50 surveys to teens participating in outreach activities over a 3-month period (July to September 2008). Staff collected surveys from a convenience sample of teens who were, to the extent possible, representative of the population they typically serve through their TSO outreach activities. UCSF provided all materials, initial training, and ongoing technical assistance to support survey administration and submission. A total of 
1,071 surveys were received, representing data from 19 of 21 TSO clinics. $^{1}$

Survey data were analyzed using Stata 9.0 software (StataCorp 2005). Data analysis was limited to surveys completed by teens aged 14-19 $(n=993,93 \%$ of total sample), the target population for all program activities. Survey weights were applied to account for differences in the number of surveys submitted by each clinic, therefore ensuring that each clinic's data were represented equally in the final results. Data were clustered at the clinic level in order to account for similarities among teen respondents within each clinic's community.

\section{Site Visits}

A team of three researchers conducted site visits at six TSO clinics that had been identified as conducting web-based outreach activities using MySpace. These visits took place in May, June, and July of 2008. The six clinics were geographically distributed across California, located in both urban and rural communities, and administered by nonprofit and public sector entities. Each site visit included two qualitative data collection activities:

\section{Interviews with Program Staff}

TSO program staff at the six clinics participated in on-site group interviews with UCSF researchers using a structured interview tool. Questions focused on the development, implementation, resource requirements, successes, and challenges of web-based outreach, as well as their perception of its effectiveness as an outreach strategy. All interviews included the program coordinator responsible for overseeing outreach activities for that clinic, as well as any adult or teen health educators who were involved in the clinic's web-based outreach. Group interviews were conducted with 22 staff at six sites. The number of staff per group ranged from two to four. All interviews were audiorecorded with participants' consent.

\section{Teen Focus Groups}

Focus groups with teens aged 14-19 were conducted at the six clinics by the UCSF researchers using a structured tool with follow-up probes. Questions addressed teens' perceptions of SNS, use of the Internet, and attitudes toward receiving health information using new technologies. Focus group participants were recruited with the help of TSO program staff; thus, most had participated in an outreach

\footnotetext{
${ }^{1}$ Funding for the TSO Program ended abruptly in September 2008 prior to the anticipated completion of this study. As a result, not all clinics were able to submit the total number of surveys requested.
}

event and/or were familiar with the TSO program. Focus groups were conducted with a total of 58 teens. The number of participants per group ranged from 6 to 14, with an average of ten per group. All focus groups were audiorecorded with participants' consent. Participants were given a $\$ 10$ gift card for their time.

After completion of the six site visits, a UCSF researcher who had not been present at the site visits, but who was highly familiar with the research protocol and aims, reviewed each of the audio-recorded sessions and created a general transcript of that session. The sessions were not transcribed verbatim in their entirety due to resource and time constraints; rather, the researcher identified and transcribed verbatim key responses, passages, and quotations related to each question. Researchers who were present at each interview and focus group reviewed these thematic notes and quotes for accuracy and completeness. The transcribed interviews and focus groups were then organized into sections based on question content so that related thematic responses were assembled for analysis. Teams of two researchers then independently reviewed, categorized, and synthesized key themes emerging in each section, returning to the audio-recorded sessions for clarification or additional depth when needed. This review structure ensured that at least two researchers reviewed all transcripts and independently identified salient themes from that section before meeting to discuss and summarize findings. Regular team meetings were held throughout the analysis to discuss findings, come to agreement about key themes identified, and address any discrepancies in individual interpretations.

\section{Results}

Teens' Access to and Use of the Internet

A diverse sample of teens participating in outreach activities completed the Teen Internet Access and Use Survey. Respondents ranged in age from 14 to 19 , with a median age of 16 . Just under half (49\%) identified as Latino, followed by $12 \%$ white, $12 \%$ mixed race/ethnicity, $11 \%$ Asian/Pacific Islander/Filipino, and 10\% African American. More than half $(60 \%)$ of respondents were female. This demographic profile is representative of the state's socio-demographic profile of low-income youth accessing subsidized family planning care and community health education efforts.

The vast majority (94\%) of teens reported using the Internet. Younger teens (aged 14-15) were significantly more likely to report having used the Internet than older teens (aged 16 and 17), but at least 90\% in all gender, age, and racial/ethnic subgroups indicated that they were at least 
occasional Internet users. Moreover, teens reported having regular access to the Internet. Half (53\%) of Internet-using teens, defined as those reporting at least occasional use, indicated that they access the Internet every day. However, this proportion varied significantly by race/ethnicity, with African American (41\%) and Latino (47\%) teens significantly less likely to access the Internet daily compared to their white (64\%) and Asian/Pacific Islander/Filipino (74\%) peers. Location of Internet access also varied significantly by race/ethnicity. Although two-thirds (67\%) of all Internetusing teens reported accessing the Internet most often from home, this figure was lower among African American (47\%), Latino (63\%), and multiracial $(66 \%)$ teens relative to white $(83 \%)$ and Asian/Pacific Islander/Filipino (89\%) teens (Table 1).

\section{Teens' Use of Social Networking Sites}

The vast majority (90\%) of Internet-using teens reported using SNS. Their use of SNS was frequent, with nearly half (46\%) reporting that they visit these sites daily. Older teens and African American teens were more likely to report using SNS than their peers (results not shown). The most popular SNS was MySpace, reported by $93 \%$ of those surveyed as the site that they use or update most often. Other sites, such as Facebook $(3 \%)$, Bebo $(<1 \%)$, and Xanga $(<1 \%)$, were selected by only a handful of teens surveyed.
Focus groups confirmed this finding; participants universally agreed that MySpace was the most commonly used SNS among their peers. In fact, MySpace's overwhelming popularity and frequency of use had made it a regular part of teens' everyday lives. As one teen commented: "If you don't have [a MySpace page], it's weird now." Another explained how integral it was for staying connected in their non-virtual life: "If you don't have one, you're left out." In interviews, program staff also gave their impressions on how MySpace had changed social interaction among the youth that they serve. One staff member described a typical information exchange between teens since the onset of MySpace: "In public, instead of 'Can I get your number?' I hear, "Can I get your MySpace?"”

Teens' Use of the Internet to Find Health Information

Surveys revealed that teens had experience searching for information online, most often related to current events or news, but also about their health. Over half $(58 \%)$ of Internet-using teens reported going online to search for information about health, dieting, or physical fitness, and $40 \%$ had used the Internet to look specifically for sexual health information. Fewer (21\%) had sought specific information about accessing sexual health services in their communities. Female teens were more likely to have looked online for general health information, sexual health infor-

Table 1 Differences in teens' overall Internet use, frequency of use, and most common location of Internet access, by gender, age, and race/ ethnicity

\begin{tabular}{|c|c|c|c|}
\hline & \multirow{2}{*}{$\begin{array}{l}\text { Overall }(N=993) \\
\text { Percent reporting daily } \\
\text { Internet use }\end{array}$} & \multicolumn{2}{|c|}{ Among Internet-using teens $(N=927)$} \\
\hline & & $\begin{array}{l}\text { Percent of frequent Internet } \\
\text { users (at least daily use) }\end{array}$ & $\begin{array}{l}\text { Percent accessing the Internet } \\
\text { most often from home }\end{array}$ \\
\hline Overall & 94 & 53 & 67 \\
\hline \multicolumn{4}{|l|}{ Gender } \\
\hline Female & 95 & 54 & 68 \\
\hline Male & 92 & 53 & 70 \\
\hline \multicolumn{4}{|l|}{ Age } \\
\hline $14-15$ & 97 & 53 & 76 \\
\hline $16-17$ & $93 * *$ & 53 & $65^{*}$ \\
\hline $18-19 *$ & 90 & 54 & $60 *$ \\
\hline \multicolumn{4}{|l|}{ Race/ethnicity } \\
\hline African American & 95 & $41^{*}$ & $47 * * *$ \\
\hline Asian/Pacific Islander/Filipino & 98 & 74 & 89 \\
\hline Latino & 93 & $47 *$ & $63 * *$ \\
\hline Biracial/Multiracial & 92 & 56 & $66^{*}$ \\
\hline Other & 92 & 59 & 71 \\
\hline White & 96 & 64 & 83 \\
\hline
\end{tabular}

Source: Teen Internet Access and Use Survey

${ }^{*} p<0.05, * * p<0.01,{ }^{* * *} p<0.001$ (compared to female, 14-15 years old, and white reference groups) 
mation, and clinic locations than male teens (Fig. 1). Similar trends were seen for older teens who sought information online more often than their younger peers. There were no differences in information seeking by race/ ethnicity, with one exception-Asian/Pacific Islander/ Filipino teens were more likely to report looking for health information online $(73 \%)$ than those of other race/ethnicities (52-62\%).

In focus groups, teens described the advantages and disadvantages of using the Internet to find health-related information. Privacy and convenience were the most often cited advantages. Teens generally agreed that the relative anonymity of the Internet made it easier to search for answers to potentially sensitive or embarrassing questions. As one teen said, "You can be anonymous. It's like you're just typing it to somebody you can't see." Teens also appreciated that the Internet was available " $24 / 7$ " and described scenarios where they might need to find the answer to a health question in the middle of the night or on the weekend. At the same time, some were uncomfortable with the prospect of relying on information found online, noting that it might not be completely accurate. They preferred instead to speak directly to someone and felt it was important for the person involved in the conversation to see their body language or hear the tone of their voice. As one teen noted, "When you type on the computer, they won't know your actions.... When you talk on the phone, they can know whether you're angry or sad."

Whether or not they were willing to access health-related information online, teens described taking specific steps to verify the accuracy of the information they found on the Internet. They expressed general distrust of the information available online, acknowledging that anyone can create a

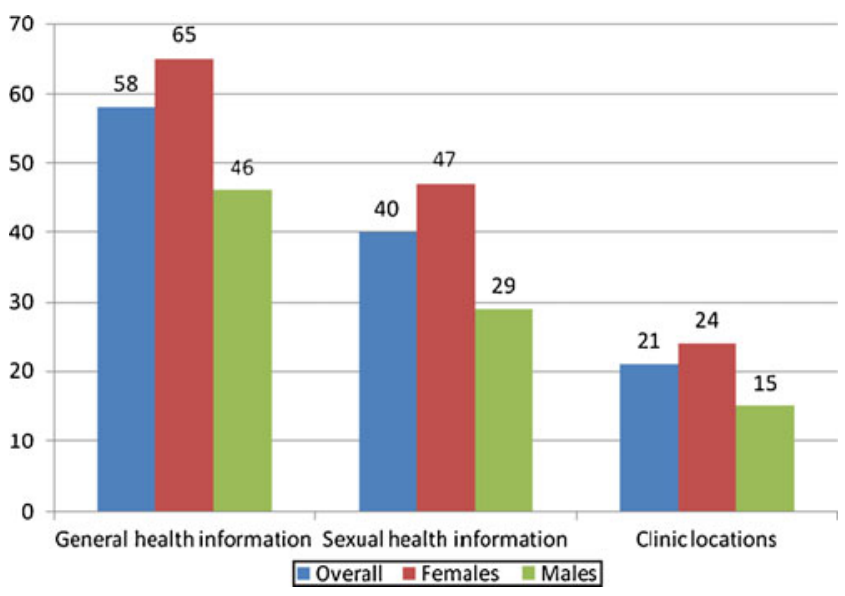

Fig. 1 Teens' willingness to search for general health information, sexual health information, and clinic locations online, overall and by gender. Source: Teen Internet Access and Use Survey, analysis limited to Internet-using teens ( $N=927,94 \%$ of the total sample). Differences by gender significant for all categories at $p<0.05$ web site or post information online. Teens considered certain web sites more trustworthy than others based on their URL type - for example, sites that ended in ".edu" or ".org" were generally seen as more reliable than those ending in ".com." User-generated sites, including Wikipedia, were cited as untrustworthy. Teens wanted to see "some sort of credentials" on a site, or links with citations and professional references, in order to trust the information. Teens expressed specific frustration with searching for sexual health information online, noting that much of the information they found online on this topic was inconsistent or unreliable.

Teens' Willingness to Receive Information Online from a Family Planning Clinic

Teens were surveyed about their willingness to receive sexual health information from a doctor or clinic through various forms of technology. Half (50\%) were very or somewhat interested in receiving information via MySpace or another SNS. A greater proportion preferred to receive information through other media, such as through a clinic's web site $(70 \%)$ or via e-mail $(60 \%$, Fig. 2$)$.

When asked specifically if they would be willing to accept a friend request on MySpace from a clinic that provides sexual health services, $41 \%$ indicated that they would. A similar percentage $(37 \%)$ were not certain, and approximately one fifth $(22 \%)$ said they would decline such a request.

Focus group data clarified these differences in opinion, with teens expressing varied perspectives on their willingness to be friends with a clinic on MySpace (Fig. 3).

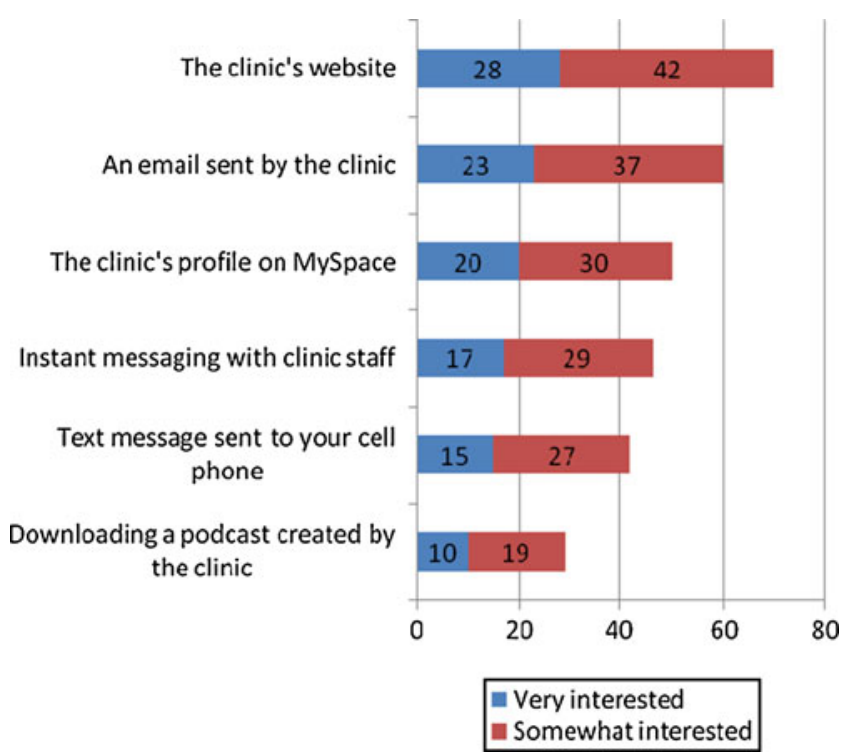

Fig. 2 Teens' interest in receiving information about sexual health from the doctor or clinic through various methods. Source: Teen Internet Access and Use Survey, $N=993$ 
Similar to their process for screening friend requests in general, most teens agreed that they would have to verify the trustworthiness and validity of the clinic and its profile before adding it as a friend to their online network. Several teens maintained that they would need to know the clinic staff or have visited the clinic previously; that is, the first contact must be more direct. Others noted that their personal interaction with the clinic was less important as long as some of their friends had already joined the clinic's network of MySpace friends. One teen described: "If they have somebody I know [as a friend], I'll accept their [invitation to be a friend]. If they don't, I'll block them."

Even those who had already "friended" a clinic or were receptive to the idea mentioned barriers that might prevent others from doing so. One frequent concern was that friends or parents might see their online connection and make assumptions about their sexual activity or health, although teens' perspectives varied. Some agreed that friending a clinic would be more acceptable if it was something that the "popular kids" in school were doing; otherwise, teens might risk rumors being spread about them. Some teens were concerned about their parents' reactions, with one noting: "If you have a clinic there [on your friend list] and they're posting bulletins about teen pregnancy, [a parent] may think, 'You might be pregnant?" Several teens had no concerns about their parents' knowing about their connection to the clinic and, in fact, felt that their parents would be supportive. Others were certain that their parents did not know how to access or use MySpace and therefore had few concerns about being discovered.

Finally, and as seen through the survey data as well, some teens expressed no interest in connecting with a clinic through a SNS for their own reasons. They described the purpose of SNS as purely social and were not interested in receiving health messages through this manner. As one teen explained: "Come on, who would talk about condoms and birth control on a MySpace page? The point is to have friends, to meet new people, not to talk about sex".

\section{Teens' Preferences for SNS Features}

Teens were asked to describe what features of a clinic's SNS would make them more receptive to becoming friends with the site. Teens agreed that some information should be transparent, such as the clinic's address and services provided, while other information, such as detailed information on sexual health topics, should be provided more discreetly. Teens expressed varied opinions on how teenfriendly to make the site. Some preferred that the SNS be professional and business-like, whereas others felt that the site should have more of a hip, youth-friendly tone. Assurances of confidentiality and non-discrimination were also important to teens. As one noted, it should be clear that
Fig. 3 Key findings from six focus group discussions with teens at Teen SMART outreach (TSO) clinics in the summer of 2008

\begin{tabular}{|c|c|}
\hline Research Domains and Emergent Themes & Salient quotes \\
\hline $\begin{array}{l}\text { Access to and use of the internet } \\
\text { Universal access and use.Internet is integrated in to teens' everyday } \\
\text { lives; almost all activities have an online component. }\end{array}$ & \\
\hline $\begin{array}{l}\text { Trustworthiness of online information } \\
\text { Default assumption is that online information is unreliable. } \\
\text { Multiple resources typically used to assess accuracy of information, } \\
\text { with weight given to information on "trusted" sites. }\end{array}$ & $\begin{array}{l}\text { "I guess it just also depends on the website where you get it from. } \\
\text { Because if I went on BBC or CNN or something, I'm pretty sure I } \\
\text { would trust that over you know, what I saw on someone's } \\
\text { [MySpace] profile." }\end{array}$ \\
\hline $\begin{array}{l}\text { Accessing sexual health in formation online } \\
\text { Anonymity and convenience/flexibility of the internet are key } \\
\text { determinants of accessing sexual health information on the } \\
\text { Internet. }\end{array}$ & $\begin{array}{l}\text { "You can always be anonymous... it's like you're just typing it to } \\
\text { somebody you can't see." } \\
\text { "Like it's there } 24 / 7 \text {. If you think something happened, you can go } \\
\text { online." } \\
\text { "When you type on the computer, they won't know your } \\
\text { actions......when you talk on the phone, they can know whether you } \\
\text { are angry or sad." }\end{array}$ \\
\hline $\begin{array}{l}\text { Use and perceptions of MySpace } \\
\text { MySpace is a "place" for teens to socialize, interact, and express } \\
\text { themselves; an extension of their non-virtual world.Use is } \\
\text { universal and frequent. }\end{array}$ & $\begin{array}{l}\text { "If you don't have MySpace, then you're not a teenager." } \\
\text { "I don't think I call most of my friends now...I would just like send } \\
\text { them a comment [on MySpace] and say, 'Come to my house." }\end{array}$ \\
\hline $\begin{array}{l}\text { Friending a sexual health clinic on MySpace } \\
\text { Willingness determined by familiarity with the clinic and } \\
\text { appearance of the website. } \\
\text { For some, MySpace is primarily a social place; (sexual) health } \\
\text { information should be on a separate website. }\end{array}$ & $\begin{array}{l}\text { "If they [a clinic's website] have informational stuff, I would probably } \\
\text { add them, so that our friends could look at it too." } \\
\text { "Come on, who would talk about condoms and birth control on a } \\
\text { MySpace page? The point is to have friends, to meet new people, } \\
\text { not to talk about sex." }\end{array}$ \\
\hline
\end{tabular}


the clinic is open to everyone regardless of "who and what you are." In a few focus groups, teens mentioned that being able to ask questions of clinic staff confidentially through the SNS messaging feature would be useful.

The Program Perspective: Resources, Advantages, and Challenges

In interviews, TSO program staff indicated that their primary motivation for using SNS as a tool for outreach was to "keep up with the times." Given MySpace's overwhelming popularity among a diverse population at the time of this study, staff saw developing their presence on MySpace as a necessary way to reach teens in their community with messages about sexual health services. As one noted, "It's a really easy way to communicate with the youth. They're constantly on the Internet via phone or computer." Another described the importance of reaching teens on their own terms, "Instead of developing something that [teens] have to get used to, we go to them." The content and features of clinics' MySpace pages generally reflected the preferences described by teens: an eyecatching and teen-friendly design, openly naming the host organization to demonstrate professional reputation, offering information about available services at clinic sites, and references to resources where teens could find answers to specific sexual health questions.

For most clinics, the idea for creating a MySpace page came from young staff- teen peer educators or young adult health educators - who recognized the popularity of MySpace among their peers. These staff were often enlisted to lead the initial development of the sites. As one coordinator explained: "If we [adult staff] were to do it, we felt it would not be very fun or animated or anything. And she [a peer educator] has experience because she has her own MySpace and a lot of her friends have MySpace."

Even with experienced teen or adult educators, most staff agreed that the initial time and expertise necessary to develop and build the site was the most challenging and time-intensive aspect of their efforts. For some clinics, the initial development took significantly longer than anticipated as they worked to garner support from higher level administrators within their organization and overcome technical hurdles. Three clinics, for example, had to address internal organizational policies that blocked access to MySpace (and other web sites) on office computers due to concerns about viruses and spam. Staff also described spending considerable time deciding what content to include on their MySpace profile and the overall tone it should adopt. Many struggled with wanting to balance representing the goals, policies, and values of their organization while still allowing for a flexible, dynamic, and teen-friendly site. In the end, four of six clinics decided to have teen or young adult staff take responsibility for deciding on content and updating the site, with regular oversight by supervisors for accuracy, appropriateness, spell checking, and formatting. Only one clinic engaged in a formal process whereby standards for web site content were developed and approved by higher level staff. All staff agreed that once the site was up and running, significantly less time was required for maintenance and updates.

\section{Building a Network of Online Friends}

Program staff described using different approaches for building their network of "friends" on MySpace. Four clinics asked teens for their e-mail or MySpace addresses on sign-in sheets at outreach events and automatically sent these teens a "friend request" through the MySpace site. Others relied on teens finding the site on their own and built their network by accepting requests initiated by teens. One clinic decided not to accept any friends in their network; as a result, their profile served as more of an informational web site than a SNS.

Clinics also developed differing policies on whether to review the pages of their friends for appropriate content. One clinic's staff felt this was necessary to ensure the teen friendliness and safety of their site. The peer educator responsible for maintaining the MySpace profile screened all friend requests and regularly reviewed the profiles of existing friends, deleting contacts who had displayed inappropriate content, such as underage drinking, substance use, or sexually suggestive behavior. In contrast, two clinics decided not to review the MySpace profiles of their friends, noting that there is an understanding among MySpace users that one's friends are not necessarily close associates and that friends' online behaviors do not necessarily reflect one's personal beliefs.

\section{Advantages to Using SNS for Outreach}

Program staff described their MySpace efforts as one component of a comprehensive plan to reach teens in their community with health information. All agreed that SNS outreach should not replace traditional in-person outreach strategies such as group presentations, street outreach, or community events. Similar to teens, program staff emphasized the importance of building an interpersonal connection first: "With real private stuff, you need that human connection...being able to relate to a voice or a person."

However, staff recognized several strengths unique to web-based outreach. First, from a logistical perspective, program staff mentioned the low cost of developing, monitoring, and maintaining the site relative to in-person outreach strategies. Second, MySpace allowed them to engage teens who might not be responsive to in-person outreach. As one coordinator explained, "A lot of times 
they're embarrassed to...just pay attention [during presentations]. They don't want somebody to laugh at them. On MySpace, they're on their own, they can look up something that they're interested in." As a result, MySpace also served as a way for staff to reinforce messages and build an ongoing relationship following an in-person contact, enabling staff to connect with teens even when they were not physically accessible.

Additionally, staff felt that the "viral" nature of MySpace provided an opportunity to connect with a larger number of teens than is possible through in-person outreach. After reaching a small number of teens on MySpace, staff noted that their online network quickly expanded. As one staff person explained, "You know that those friends that you have will see that, and their friends will see that, and their friends will see that....You're reaching a chain of teens." The impact for one clinic was immediate, "The kids are coming after school to the front desk and saying, 'Can I get some condoms?...I saw on the computer that I can get some here."

Finally, having a presence on MySpace helped some clinics build their reputation as a teen-friendly place. Program staff at one clinic described teens' excitement upon learning that the clinic had a MySpace page, leading one to exclaim, "Maybe you are cool!" The staff recognized this and made specific efforts to tailor their site accordingly, "MySpace is about entertainment, about being on the edge, being social, and connecting with people. So, we're trying to make it more cruising-friendly if you're on the computer just trying to have a good time."

\section{Challenges in Using SNS for Outreach}

One of the most significant challenges described by staff was learning how to adapt this new technology to reach teens with health-related messages. Without prior experience using SNS as an outreach strategy, the staff described devoting significant time and energy to deciding how their profile should look, what content should be included, and how often to update the site. In addition, many had to gain the support of higher level administrators within their organization who were unfamiliar with or had negative perceptions of SNS, overcome technical challenges to accessing and using the web site, and learn how to take advantage of MySpace features that interest teens. Without the involvement of young staff, the technological aspects of developing and maintaining the site would likely have prevented one clinic from developing a MySpace page, "We depend on our [peer educator], and even she has a limitation on what she can do on MySpace... and us, we're just bear-headed when it comes to it. We try, we get frustrated." Another clinic described ongoing discussions to decide what content should be included on their profile, questioning, "Will [teens] shy away if we talk about birth control?"

Negative public perceptions of MySpace also presented a challenge to some clinics. Although none had encountered any significant problems with hacking or victimization, all remained concerned about the possibility of such events. All clinics reported spending time reviewing their profiles to ensure that the content was appropriate to a wide range of teens; however, some struggled with finding a balance between allowing visitors to have creative freedom in using the site and ensuring that the site's content was appropriate and reflected the clinic's mission. Several staff were surprised by the frequency with which they had to update their MySpace content in order to keep teens' interest. One coordinator expressed concern about the longevity of MySpace's popularity, "The minute you figure out what they are up to, they've moved on to the next thing."

\section{Discussion}

As noted recently by the Institute of Medicine, the current system of health services and settings in the USA is poorly equipped to meet the diverse health needs of adolescents (Lawrence et al. 2009). For sexual health care in particular, adolescents face numerous barriers related to confidentiality, cost, and accessibility of services (Brindis 2006). It is critical to find new and innovative models for increasing access to sexual health services for all teens, specifically those at greatest risk for unintended pregnancy and sexually transmitted infections. Even in California, where the Family PACT Program ensures that comprehensive and confidential sexual health services are available to teens, awareness of this resource is often limited among the populations most in need. Thus, outreach becomes an important step toward increasing access to health services and improving health outcomes.

A key feature of successful health outreach is connecting with target populations in their own environments-where they live, learn, work, and play. This study explored the potential of SNS as an outreach strategy for connecting teens to the sexual health services available, but often unknown, to them in their communities. It examined the patterns of Internet and SNS use among teens in select communities in California, as well as their willingness to be reached by a clinic through a SNS, in order to better understand the likelihood for success of web-based outreach in these settings. The study also described the resources required for undertaking such an effort and the common challenges in its development and implementation faced by program staff at six geographically diverse family planning clinics. 
While concerns over a "digital divide" have been extensively discussed in the past, this study found widespread access to and use of the Internet among a diverse sample of teens living in low-income communities across California. These findings are consistent with a growing body of research suggesting that inequalities in overall Internet access by socioeconomic status and gender are shrinking (Livingstone and Helsper 2007). Nonetheless, this study found racial/ethnic disparities in the frequency of use and location of access to the Internet, with African American and Latino teens significantly less likely to frequently use the Internet and access the Internet from home. Such differences in frequency and location of access may have a substantial impact on the types of online activities that teens can engage in and the extent to which they can obtain information quickly and privately at a time that might be most convenient for them, for example on weekends and late at night when access to public locations would be more restricted. Additional research on how location of access impacts teens' use of the Internet, especially given rapid uptake of mobile technology by diverse youth, is necessary to better understand the impact of these disparities and how these are changing over time.

Findings also confirmed teens' willingness to seek information about their personal health online. Four out of ten teens surveyed had looked specifically for sexual health information online, and one in five had used the Internet to locate a clinic in their community where they could access sexual health services. Notably, these findings were similar across diverse racial/ethnic groups, mirroring other studies on information-seeking behaviors among teens (Zhao 2009). The teens in this study described unique advantages to using the Internet to find health-related information, including its privacy, anonymity, and convenience. At the same time, they expressed concerns about the accuracy of the information available online, a finding that is not surprising given other research highlighting inconsistencies in the quality and comprehensiveness of online health information (Gray et al. 2005). Given the wealth and diversity of information already available online, it is critical that those developing new web sites aimed at youth consider their unique contribution and role.

User-generated, interactive web sites such as MySpace and other SNS clearly have tremendous appeal for teens today. This study highlighted the nearly universal presence of MySpace and other technology in the lives of teens, even those living in lower income communities. The vast majority of teens surveyed had developed a profile on MySpace, and in focus groups, they described communicating with friends, sharing information, and exploring new interests through the site. Whether they viewed SNS as a suitable forum for receiving information about sexual health varied, with half showing interest in receiving health information through a SNS. When asked specifically if they would be willing to accept a friend request on a SNS from a clinic that provides sexual health services, $41 \%$ indicated that they would. There is still a large proportion of teens who are not ready to engage in this approach, either because they view SNS as more appropriate for social interaction, have concerns about peer or parental reactions, or prefer to connect with health professionals face-to-face. These varied preferences have been noted in other studies (Bambling et al. 2008) and were reflected in program staff's description of their challenges building their network on MySpace. Continued attention to this issue is warranted given the dynamic nature of SNS. Recently, numerous social networking web sites have been at the center of controversy regarding how to protect users' privacy while maintaining the public and social nature of the sites. These ongoing changes may increase an individual's willingness to share health or other personal information online, or they may drive users away from the site entirely.

Still, the ability to engage even half of teens through SNS may be considered a success, particularly if complemented by other outreach approaches. In making health-related decisions, individuals typically consult multiple resources and may have to hear messages through multiple venues before changing their behaviors. Although physicians and parents consistently rank as the most trusted source of information for teens, there is increasing evidence that the Internet serves an important function of reinforcing or triangulating the information conveyed through other sources (Oh et al. 2005; Eysenbach 2008). As a result, although the Internet may not be the most trusted source of health information, it appears to be an increasingly popular part of an individual's health decision-making process, including decision making around reproductive health (Yee and Simon 2010).

There are many potential benefits of SNS outreach. Through a clinic's SNS, teens can find information vetted by a reputable health provider, reducing the challenges of inaccuracy and "information overload" offered by the Internet. Teens in particular value information that is quickly accessible (Ybarra and Suman 2008), and SNS are well-suited to deliver information in this format. Having a presence on a SNS can also establish a clinic's reputation as a teen-friendly place, allowing youth to familiarize themselves with the clinic policies regarding confidentiality and cost, services available to them, and sometimes even staff members who they will encounter during their clinic visit. SNS can also serve as a unique way in which to engage hard to reach youth, including those that are hesitant or unable to ask questions during in-person outreach and who prefer the privacy and anonymity of the Internet. Finally, using SNS as an outreach strategy offers programs the opportunity for youth involvement by engaging local teens in the development, review, and maintenance of their SNS efforts. 
However, before engaging in SNS outreach, it is critical for programs to conduct their own needs assessmentsensuring that teens in their communities have access to the technology and are willing to engage with a health educator or clinician through these mechanisms. This formative work is particularly critical given the rapid development of new technologies and fluidity in teens' preferences for online activities. As new and varied forms of technology become established in teen culture, youth-serving programs need to stay attuned to these changes and consider whether such tools should be used in conjunction with their traditional approaches. Regarding SNS specifically, a recent study found declining use of MySpace in a sample of over 1,400 adolescents followed over a period of 2 years (Patchin and Hinduja 2010). It is unclear at this time whether these youth are joining other online social networks such as Facebook or simply losing interest in SNS sites altogether. These changes in social media are clearly organic and move quickly, so it is critical that the lessons and insights learned from MySpace-or any specific technology — be considered in the development of the next generations of social media, which are likely to continue to evolve over time and in new cohorts of adolescents.

Several limitations of the current study must be considered while interpreting these findings. First, survey and focus group participants were selected with the help of program staff and thus represent a convenience sample. Specific guidelines regarding representative sampling strategies were shared with all program staff, but in the end, the program staff administered surveys at their discretion. As a result, the findings from this study are not necessarily representative of all teens participating in TSO programs or of teens in California more generally. Second, although the TSO program was designed to serve teens in low-income communities, socioeconomic data were not collected to confirm income status. Third, time and resource constraints prohibited verbatim transcription of all focus group and interview data. Independent reviews of all taped sessions and notes by at least two researchers, as well as regular discussion among study staff regarding interpretation of findings, were conducted to ensure accurate and consistent reporting of results despite this methodological limitation. Fourth, data collection for this study occurred in the summer of 2008 when MySpace was the most popular SNS among teens. Recognizing the dynamic and evolving nature of the Internet and SNS, it is important that these findings be considered in the context of the time period in which the data were collected. Finally, the researchers made an explicit decision to design an exploratory study given the relative infancy of this approach among the clinics being evaluated. That is, this study represents an initial attempt to explore the potential for SNS, specifically MySpace, to be used as one in a portfolio of strategies to reach teens with critical health messages. Should such efforts continue and expand based on the findings of this preliminary study, an investment in a comprehensive evaluation is warranted.

Overcoming the multitude of barriers that teens face in accessing sexual and other types of health services will require that youth-serving programs adopt innovative and unique strategies and venues for connecting with teens in their communities. Online approaches, including the use of SNS, have the potential to engage diverse segments of the population and provide youth with the resources they need to navigate their adolescence and avoid pregnancy and STIs. Other web-based tools, including text and e-mail reminders for contraceptive use or clinic appointments, anonymous notification of exposure to STIs, links to local sources of treatment, and podcasts and/or other short videos on reproductive health topics could be integrated into MySpace or other SNS, further increasing youth's access to this important information (Levine 2009). Although technology should never replace the in-person interaction between youth and health care educators and providers, it has tremendous potential to complement and reinforce health messages and reach youth on their own terms.

Acknowledgments This study was funded by the State of California Department of Public Health, Office of Family Planning, through a contract with the University of California, San Francisco. Dr. Brindis' time is supported in part by grants from the Maternal and Child Health Bureau, Health Resources and Services Administration, U.S. Department of Health and Human Services (U45MC 00002, and U45MC 00023). The authors wish to thank the former TeenSMART Outreach grantees for their innovative work and contributions to this study, as well as Ayesha Appa for her research assistance during data collection.

Open Access This article is distributed under the terms of the Creative Commons Attribution Noncommercial License which permits any noncommercial use, distribution, and reproduction in any medium, provided the original author(s) and source are credited.

\section{References}

Bambling, M., King, R., Reid, W., \& Wegner, K. (2008). Online counseling: The experience of counselors providing synchronous single session counseling to young people. Counseling and Psychotherapy Research, 8, 110-116.

Berson, I. R., Berson, M. J., \& Ferron, J. M. (2002). Emerging risks of violence in the digital age: Lessons for educators from an online study of adolescent girls in the United States. Journal of School Violence, 1, 51-71.

Borzekowski, D., \& Rickert, V. (2000). Urban girls, Internet use, and accessing health information. Journal of Pediatric and Adolescent Gynecology, 13, 94-95.

Borzekowski, D., \& Rickert, V. (2001). Adolescent cybersurfing for health information: A new resource that crosses barriers. Archives of Pediatric and Adolescent Medicine, 155, 813-817.

Boyd, D. (2007). Identity production in a networked culture: Why youth heart MySpace. In D. Buckingham (Ed.), Youth, identity, and digital media. Cambridge: The MIT Press. 
Brindis, C. (2006). A public health success: Understanding policy changes related to teen sexual activity and pregnancy. Annual Review of Public Health, 27, 277-295.

Eysenbach, G. (2008). Credibility of health information and digital media: New perspectives and implications for youth. In M. Metzger \& A. Flanagin (Eds.), Digital media, youth, and credibility. The John D. and Catherine T. MacArthur Foundation Series on Digital Media and Learning. Cambridge: The MIT Press.

Gray, N. J., \& Klein, J. D. (2006). Adolescents and the Internet: Health and sexuality information. Current Opinion in Obstetrics \& Gynecology, 18, 519-524.

Gray, N. J., Klein, J. D., Noyce, P. R., Sesselberg, T. S., \& Cantrill, J. A. (2005). The Internet: A window on adolescent health literacy. Journal of Adolescent Health, 37, 243e1-243e7.

Griffiths, F., Lindenmeyer, A., Powell, J., Lowe, P., \& Thorogood, M. (2006). Why are health care interventions delivered over the Internet? A systematic review of the published literature. Journal of Medical Internet Research, 8, e10.

Guan, S. A., \& Subrahmanyam, K. (2009). Youth Internet use: Risks and opportunities. Current Opinion in Psychiatry, 22, 351-356.

Gustafson, D., Robinson, T., Ansley, D., Adler, L., Brennan, P., \& the Science Panel on Interactive Communication and Health. (1999). Consumers and evaluation of interactive health communication applications. American Journal of Preventive Medicine, 16(1), 23-29.

Ito, M., Horst, H., Bittanti, M., Boyd, D., Herr-Stephenson, B., Lange, P., et al. (2008). Living and learning with new media: Summary of findings from the Digital Youth Project. In D. John \& T. Catherine (Eds.), MacArthur foundation reports on digital media and learning. Cambridge: The MIT Press.

Kanuga, M., \& Rosenfeld, W. (2004). Adolescent sexuality and the Internet: The good, the bad, and the URL. Journal of Pediatric and Adolescent Gynecology, 17, 117-124.

Keller, S., Labelle, H., Karimi, N., \& Gupta, S. (2002). STD/HIV prevention for teenagers: A look at the universe. Journal of Health Communication, 7, 341-353.

Lawrence, R. S., Gootman, J. A., \& Sim, L. J. (Eds.). (2009). Adolescent health services: Missing opportunities. Washington: The National Academies Press.

Lenhart, A., \& Madden, M. (2007). Social networking websites and teens. Washington: Pew Internet \& American Life Project.

Lenhart, A., Purcell, K., Smith, A., \& Zickuhr, K. (2010). Social media and mobile Internet use among teens and young adults. Washington: Pew Internet \& American Life Project.

Levine, D. (2009). Using new media to promote adolescent sexual health: Examples from the field. prACTice Matters. Ithaca: ACT for Youth Center for Excellence.

Livingstone, S., \& Helsper, E. (2007). Gradations in digital inclusion: Children, young people, and the digital divide. New Media \& Society, 9, 671-696.

Mitchell, K., Wolak, J., \& Finkelhor, D. (2007). Trends in youth reports of sexual solicitations, harassment and unwanted exposure to pornography on the Internet. The Journal of Adolescent Health, 40, 116-126.
NY1. (2008). Department of Health page on MySpace nets more than 11,000 hits. Retrieved from http://www.ny1.com/ Default.aspx?SecID=1000\&ArID=83693.

Oh, M. K., Spivey, C., Simpson, T., Vazin, T., Grimley, D. M., \& Gunn, K. (2005). Source of sexual health information in adolescence is associated with beliefs and knowledge of reproductive health in young adults. The Journal of Adolescent Health, 36, 147.

Patchin, J. W., \& Hinduja, S. (2010). Trends in online social networking: Adolescent use of MySpace over time. New Media \& Society, 12, 197-216.

Rideout, V., Foehr, U., \& Roberts, D. (2010). Generation $M^{2}$ : Media in the lives of 8-to 18-year olds. Menlo Park: The Kaiser Family Foundation.

Roberto, A. J., Zimmerman, R. S., Carlyle, K. E., \& Abner, E. L. (2007). A computer-based approach to preventing pregnancy, STD, and HIV in rural adolescents. Journal of Health Communication, 12, 53-76.

Skinner, H., Biscope, S., Poland, B., \& Goldberg, E. (2003). How adolescents use technology for health information: Implications for health professionals from focus groups. Journal of Medicine and Internet Research, 5, e32.

Smith, M., Gertz, E., Alvarez, S., \& Lurie, P. (2006). The content and accessibility of sex education information on the Internet. Health Education \& Behavior, 27, 684-694.

StataCorp. (2005). Stata statistical software: Release 9. College Station: StataCorp LP.

Stretcher, V. (2007). Internet methods for delivering behavioral and health-related interventions (eHealth). Annual Review of Clinical Psychology, 3, 53-76.

Subrahmanyam, K., \& Greenfield, P. (2008). Virtual worlds in development: Implications of social networking sites. Journal of Applied Developmental Psychology, 26, 407-417.

Versteeg, K. M., Knopf, J. M., Posluszny, S., Vockell, A. B., \& Britto, M. (2009). Teenagers wanting medical advice: Is MySpace the answer? Archives of Pediatric and Adolescent Medicine, 163, 91-92.

Ybarra, M., \& Mitchell, K. (2007). How risky are social networking sites? A comparison of places online where youth sexual solicitation and harassment occurs. Pediatrics, 121, e350-e357.

Ybarra, M., \& Suman, M. (2008). Reasons, assessments and actions taken: Sex and age differences in uses of Internet health information. Health Education Research, 23, 512-521.

Ybarra, M., Mitchell, K., Finkelhor, D., \& Wolak, J. (2007). Internet prevention messages: Targeting the right online behaviors. Archives of Pediatric \& Adolescent Medicine, 161, 138-145.

Yee, L., \& Simon, M. (2010). The role of the social network in contraceptive decision-making among young, African American and Latina women. Journal of Adolescent Health, 47, 374-380. Retrieved 29 May 2010 from http://www.jahonline.org/article/ S1054-139X\%2810\%2900170-9/pdf.

Zhao, S. (2009). Parental education and children's online health information seeking: Beyond the digital divide debate. Social Science \& Medicine, 69, 1501-1505. 